\title{
Ground-penetrating radar insight into a coastal aquifer: the freshwater lens of Borkum Island
}

\author{
J. Igel ${ }^{1}$, T. Günther ${ }^{1}$, and M. Kuntzer ${ }^{2}$ \\ ${ }^{1}$ Leibniz Institute for Applied Geophysics (LIAG), Hanover, Germany \\ ${ }^{2}$ Institute for Soil Science, Leibniz University Hannover, Hanover, Germany \\ Correspondence to: J. Igel (jan.igel@liag-hannover.de)
}

Received: 2 March 2012 - Published in Hydrol. Earth Syst. Sci. Discuss.: 16 March 2012

Revised: 21 December 2012 - Accepted: 14 January 2013 - Published: 7 February 2013

\begin{abstract}
Freshwater lenses, as important resource for drinking water, are sensitive to climate changes and sea level rise. To simulate this impact on the groundwater systems, hydraulic subsurface models have to be designed. Geophysical techniques can provide information for generating realistic models. The aim of our work is to show how groundpenetrating radar (GPR) investigations can contribute to such hydrological simulations. In the pilot area, Borkum island, GPR was used to map the shape of the groundwater table (GWT) and to characterise the aquifer.

In total, $20 \mathrm{~km}$ of constant offset (CO) profiles were measured with centre frequencies of 80 and $200 \mathrm{MHz}$. Wave velocities were determined by common midpoint (CMP) measurements and vertical radar profiling (VRP) in a monitoring well. The $80 \mathrm{MHz} \mathrm{CO}$ data show a clear reflection at the groundwater table, whereas the reflection is weaker for the $200 \mathrm{MHz}$ data. After correcting the GPR water tables for the capillary rise, they are in good accordance with the pressure heads of the observation wells in the area. In the centre of the island, the groundwater table is found up to $3.5 \mathrm{~m}$ above sea level, however it is lower towards the coastline and marshland. Some local depressions are observed in the region of dune valleys and around pumping stations of the local water supplier. GPR also reveals details within the sediments and highly-permeable aeolian sands can be distinguished from less-permeable marine sediments. Further, a silt loam layer below the water table could be mapped on a large area. The reflection characteristics indicates scattered erosion channels in this layer that cause it to be an aquitard with some leakage.

GPR provides a high resolution map of the groundwater table and insight into the stratigraphy of the sediments and
\end{abstract}

their hydraulic properties. This is valuable complementary information to the observation of sparsely distributed monitoring wells as input to hydraulic simulation.

\section{Introduction}

Freshwater lenses are an important resource for drinking water on islands and coastal areas. The balance of freshwater and saltwater in those environments is very sensitive to changes of the basic conditions. Within the CLIWAT project (CLImate and WATer, http://www.cliwat.eu), the impact of climate change and sea level rise on freshwater resources of coastal aquifers is investigated by long-term hydraulic simulations (Sulzbacher et al., 2012).

When rainwater seeps through the ground surface of an island, it cumulates in the subsurface. Due to its lower density, the freshwater floats on top of the saltwater and forms a freshwater lens analogous to an iceberg floating in the sea. Only a small part of the freshwater lens emerges above the sea level whereas the larger part is below. The correlation between the thickness of the freshwater lens and the height of the groundwater table above sea level was first observed and described by Ghyben and Herzberg (Herzberg, 1901):

$h=\frac{\rho_{\mathrm{s}}-\rho_{\mathrm{f}}}{\rho_{\mathrm{f}}} z$,

where $h$ is the height of the groundwater table above sea level (a.s.l.), $z$ the thickness of the freshwater lens below sea level, and $\rho_{\mathrm{s}}=1.025 \mathrm{~g} \mathrm{~cm}^{-3}$ and $\rho_{\mathrm{f}}=1 \mathrm{~g} \mathrm{~cm}^{-3}$ the density of salt- and freshwater, respectively. When using these 
values, Eq. (1) leads to $z=40 h$. However, this relationship is only valid for a homogeneous subsurface and stationary conditions.

Hydrogeologic models are usually founded on general geologic information as well as data from drill cores, monitoring wells, and pumping tests. Besides, a variety of geophysical techniques were evaluated within the CLIWAT project with regard to their capability to give further valuable information on large areas like hydraulically relevant subsurface structures, hydraulic properties and the shape of the freshwater lens. The geophysical techniques include seismics, airborne electromagnetics (Siemon et al., 2009), electrical resistivity tomography (ERT) from the surface as well as in boreholes (Grinat et al., 2010), magnetic resonance soundings (MRS) (Günther and Müller-Petke, 2012), direct push techniques, and ground-penetrating radar (GPR).

GPR has shown to be a powerful tool for environmental and hydrogeologic investigations, particularly in rocks and sediments with low electrical conductivity. It is successfully used for high-resolution investigations in sedimentology and landform characterisation (Bristow et al., 2000; Neal, 2004; van Dam, 2012) and showed to be an outstanding tool for mapping large-scale architecture and small-scale internal structures in coastal barriers (Møller and Anthony, 2003; Nielsen et al., 2009; Bennett et al., 2009; Lindhorst et al., 2010). GPR has also proven its ability to detect groundwater tables in sandy aquifers (Harari, 1996; Doolittle et al., 2006; Rejiba et al., 2012). Tronicke et al. (1999) investigated the freshwater lens of a barrier island by a combination of electrical resistivity soundings and GPR. They constructed a groundwater contour map for the island of Spiekeroog from observation wells and GPR at single points where the groundwater table was clearly identifiable and the height of the ground surface was known. Kruse et al. (2000) investigated a very thin $(1-1.5 \mathrm{~m})$ freshwater lens on Key Largo, Florida, with GPR and obtained a strong water table reflection followed by a weak reflection from the transition zone from fresh- to saltwater below.

The island of Borkum was one of the pilot areas that was intensely investigated within the CLIWAT project. Borkum is the largest and westernmost island of the East Frisian islands chain along the German North Sea coast (Fig. 1). It covers an area of $31 \mathrm{~km}^{2}$ and is located $10 \mathrm{~km}$ north of the mainland. It is a typical barrier island with dunes at the northern open sea side and a low marshland at the southern land side. The geology of the island is based on the interaction of tidal and climatic sea level variation and a prevailing western wind direction. The underground of the island is built by Holocene sandy sediments. Primarily, it was an alluvial formation deposited by the sea. Its topography was formed by the wind, causing the development of dunes. The deposits consist predominantly of quartz sand with interfered layers of peat, clay, silt and shell detritus in places. The basis of these formations is situated at approx. $20 \mathrm{~m}$ below sea level (b.s.l.) and consists of glacial sediments from the Pleistocene period (Keilhack and Wildvang, 1925).

The aim of this paper is to evaluate the capability of GPR to investigate the near-surface aquifer of Borkum island and to demonstrate the benefit of GPR investigation as a part of geophysical exploration for realistic hydraulic simulation of future developments of an island freshwater lens (Sulzbacher et al., 2012). The central and eastern part of the island was selected as the survey site. In the central part, the number of boreholes and observation wells was small and there was only little information on the structure of the shallow subsurface and the shape of the freshwater lens. Hence, there was a high demand for further information from hydrologists and the local water supplier. In the eastern part, where the production wells of the water work are located, the observation-well density is higher and this area could therefore be used for evaluation and calibration of GPR data. The survey site covers a large range of topographic elevations from low-lying areas up to the highest dunes of the island (see Fig. 1). As a consequence, the range of GWT levels is large and also includes the depression cones of the production wells. This makes the selected area of the island well suited for evaluating the feasibility and benefit of GPR investigations.

Main targets of interest are the groundwater table of the freshwater lens and the location of clayey/silty layers in the sandy sediments that act as aquitards. Besides the existance of these layers also their characteristics are of interest for hydrological studies, e.g., whether they are continuous or show gaps leading to leakage.

First, the methodology will be explained and a technical description of the GPR investigations and sample analysis will be given. Then, the results will be discussed and interpreted in a hydrogeological context. Hydraulically relevant structures and material properties will be deduced that contribute to the design of a hydraulic model of the island.

\section{Methods and experiments}

\subsection{Velocity determination}

An essential step of every GPR survey is to determine the radar-wave velocities in the subsurface. As in seismics, the velocity is needed to transform travel times into depths and a good velocity model is fundamentally important for proper processing and to deduce a quantitative structural map of the underground. Radar velocities $v$ depend on dielectric permittivity $\varepsilon_{r}$ and for low-loss materials this relation is given by

$v=\frac{c}{\sqrt{\varepsilon_{r}}}$,

where $c$ is the speed of light in vacuum. Permittivity is linked to further material properties as primarily water content, porosity and, to a lower degree, the mineral composition of the grains (e.g., Topp et al., 1980). One often used formula 

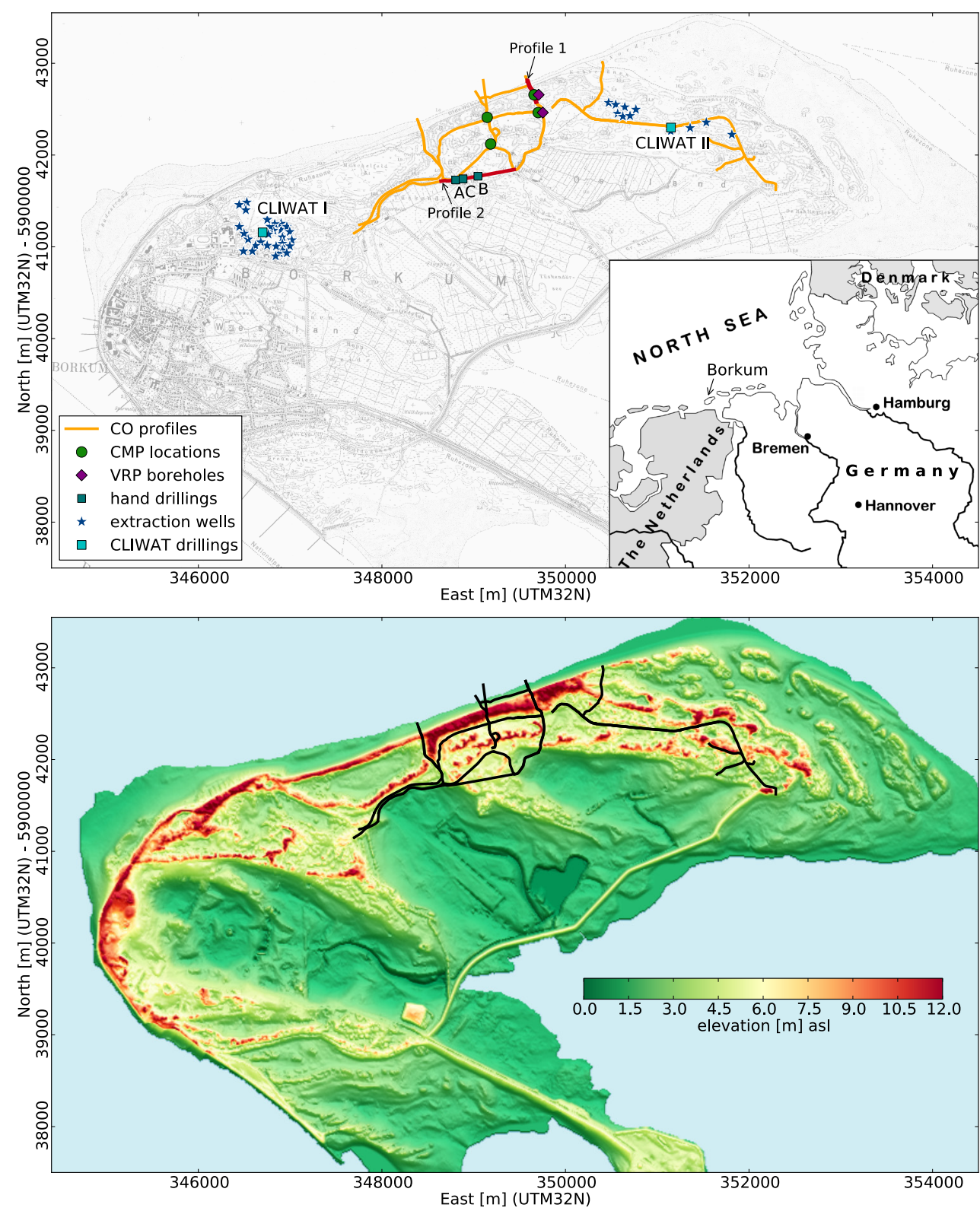

Fig. 1. Map of Borkum island showing the CO GPR profiles, locations of CMP and VRP soundings, hand drillings (A, B, C) as well as the CLIWAT research boreholes and water supply wells of the waterworks (left). The highlighted CO profiles 1 and 2 are discussed in detail in the following. Map of Borkum island showing the topography and the CO profiles (right).

is based on the complex refractive index method (CRIM). It relates the volumetric fractions of the sediment compounds, the solid matrix, the water and air that fill the pore space and their particular permittivities to the bulk permittivity of the mixture (Shen et al., 1985):

$\sqrt{\varepsilon_{r}^{\mathrm{bulk}}}=(1-\Phi) \sqrt{\varepsilon_{r}^{\mathrm{m}}}+\theta_{V} \sqrt{\varepsilon_{r}^{\mathrm{w}}}+\left(\Phi-\theta_{V}\right) \sqrt{\varepsilon_{r}^{\mathrm{a}}}$.

$\Phi$ is the porosity, $\theta_{V}$ the volumetric water content and $\varepsilon_{r}^{\mathrm{m}}$, $\varepsilon_{r}^{\mathrm{W}}$, and $\varepsilon_{r}^{\mathrm{a}}=1$ are the permittivities of matrix, water, and air, respectively. Thus, reliable velocity values can be used to characterise rocks and sediments and to deduce hydraulically relevant properties: water content, and porosity in case of saturated sediments.

Two techniques that originally stem from seismics had been adapted for GPR and were used in this study to assess wave velocities.

\subsubsection{CMP soundings}

Common midpoint (CMP) measurements are a common tool to deduce wave velocities in the subsurface. In case of GPR, 
transmitter and receiver antenna are stepwise separated from a constant midpoint and at each distance a trace is recorded (e.g., Annan, 2005). The shape of reflection hyperbolas depends on the mean radar velocity above the reflector. In case of an adequate number of reflectors in the subsurface, the interval velocities between these reflectors can be calculated and a velocity-depth model can be deduced.

CMP measurements were carried out at 4 locations in the area of the GPR investigations (see Fig. 1). Figure 2a shows an example acquired with unshielded $80 \mathrm{MHz}$ antennas (GSSI MLF antenna) on top of a dune with antenna offsets of $1-39 \mathrm{~m}$ and $0.5 \mathrm{~m}$ intervals. Static correction and amplitude balancing (removal of header gain and divergence compensation) has been performed. The air wave can clearly be recognised as primary onset in the CMP section followed by critically refracted waves, the ground wave and several reflected waves. Figure $2 b$ shows the results of a semblance analysis that is used to find the mean velocity and travel time of reflections in the GPR section. The energy along calculated reflection hyperbolas is summed up for every combination of travel time and mean velocity, and a reflection at a plain surface is focused to a point in the semblance plot (Yilmaz, 2001). The air wave appears as an energy maximum at $t=0 \mathrm{~ns}$ and $v=0.3 \mathrm{mns}^{-1}$ and reflected waves appear at longer travel times and lower mean velocities. The energy maxima are picked in the semblance plot and then the position and shape of a synthetic hyperbola (red curves in Fig. 2a) are manually fitted to the reflections in the CMP section by varying the depth of the interface as well as the mean velocity of the overlaying. Then, a velocity-depth-model is calculated by using the Dix-formula (Dix, 1955) and by transforming the mean velocities to interval velocities between the reflectors (Fig. 2c). The velocity is quite constant at $0.12 \mathrm{mns}^{-1}$ for the shallow subsurface representing the unsaturated zone. At approx. $200 \mathrm{~ns}$ the velocity shows a steep decrease to $0.065 \mathrm{~m} \mathrm{~ns}^{-1}$, which corresponds to the water-saturated sand below the groundwater table. The CMPs at the other locations show quite similar results with velocities of 0.12 and $0.065 \mathrm{~m} \mathrm{~ns}^{-1}$ for the unsaturated and saturated sand, respectively, differing by $\pm 10 \%$.

CMP soundings have the advantage that they do not need any well and can be carried out at favoured locations in an area. However, drawbacks are a limited accuracy and that CMPs can only provide velocities between distinct reflectors, i.e. the vertical resolution may be bad depending on geology.

\subsubsection{VRP soundings}

Subsurface radar velocities can be accurately determined by GPR borehole measurements as the propagation path of the waves is a priori known. Tomographic crosshole measurements can provide detailed subsurface models (e.g., Tronicke et al., 2004; Ernst et al., 2007; Klotzsche et al., 2010. However, this method requires a significant effort and at least two boreholes at a very short distance, which is rarely found in the field. Vertical radar profiling (VRP) needs only one borehole, e.g., every groundwater monitoring well in which a borehole antenna fits $\left(\geq 2^{\prime \prime}\right)$ can be used as long as plastic tubes were installed. One antenna is lowered in the borehole and the other antenna is placed at the ground surface. It is similar to vertical seismic profiling (VSP), a wellestablished technique for deducing seismic velocity models (Hardage, 2000). In hydrogeophysics, VRP has successfully been used, e.g., to obtain a moisture content profile in a landfill to assess its capping effectiveness (Cassiani et al., 2008).

Vertical radar profiling measurements were carried out in two monitoring wells located on top of a dune and in a dune valley (see Fig. 1). A Malå RAMAC $100 \mathrm{MHz}$ slimhole receiver was placed in the borehole and a $100 \mathrm{MHz}$ unshielded surface transmitter was placed at different offsets from the hole in radial polarisation direction. At every transmitter offset, the receiver was lowered down the borehole and a trace was recorded every $10 \mathrm{~cm}$.

Besides direct waves that propagate on the shortest way from transmitter to receiver, refracted waves may occur that first propagate through air to the borehole and then down to the receiver. For larger offsets, these waves are faster than the direct wave and cause interferences, wherefore near-offset transmitter positions are preferred (Tronicke and Knoll, 2005). On the other hand, short offsets result in weak GPR amplitudes due to the different polarisation of surface and borehole antenna and the resulting radiation pattern. When assuming ideal infinitesimal dipoles, the simple multiplication of the radiation pattern of the co-polarised transmitting and receiving antenna results in a very poor sensitivity for small offsets and weak amplitudes are expected. Thus, there is a trade-off between the requirement to avoid waves critically refracted at the earth's surface and the quest to record high amplitude data (Tronicke and Knoll, 2005). However, real borehole antennas are not ideal dipoles and still have a considerable sensitivity in dipole direction and we could not observe a significant rise in amplitudes with increasing transmitter offset. Thus, we used an offset of $1 \mathrm{~m}$, which showed the best data quality for further analysis.

A dewow filter was applied (10 ns running mean) in order to remove low frequency noise and the traces were normalised (Fig. 3a). The first-arrival times were picked and inverted using a smoothness-constrained Gauss-Newton algorithm similar to Clement and Knoll (2006) assuming straight rays between transmitter and receiver. Regularisation strength was subsequently reduced and the roughness of the velocity curve was iteratively used as weighting factor in order to achieve sharp contrasts, e.g., at the groundwater table (Fig. 3b, c). The model shows a sharp decrease of radar velocity at the groundwater table with a quite homogeneous velocity of $0.121-0.132 \mathrm{~m} \mathrm{~ns}^{-1}$ in the unsaturated zone above and $0.064-0.065 \mathrm{mns}^{-1}$ in the saturated zone below. The groundwater table in the monitoring well was measured with a light plummet and is plotted in Fig. $3 \mathrm{~b}$ and c. 

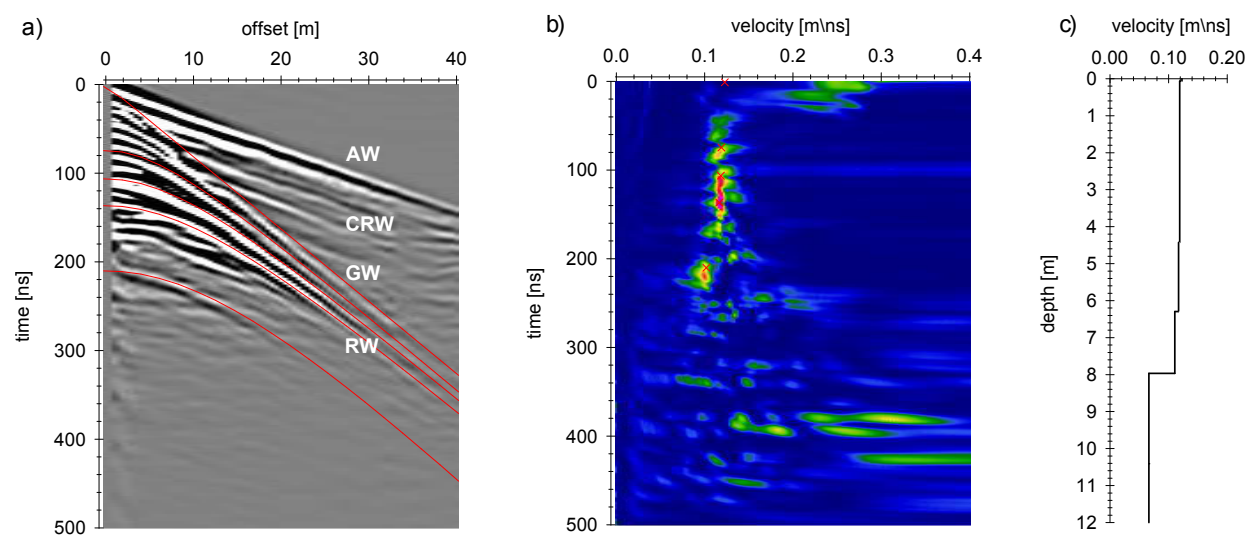

Fig. 2. CMP radar section (80 MHz centre frequency) on top of a dune (a), semblance velocity analysis (b) and deduced velocity model (c). In (a), the different wave types are indicated: direct air wave (AW), critically refracted waves (CRW), ground wave (GW) and reflected waves (RW).

a)

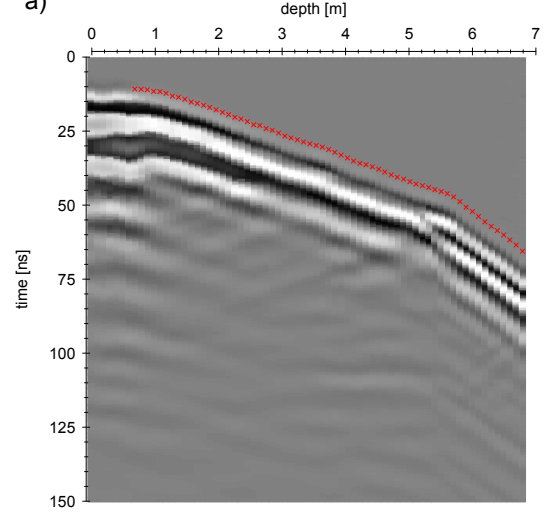

b)

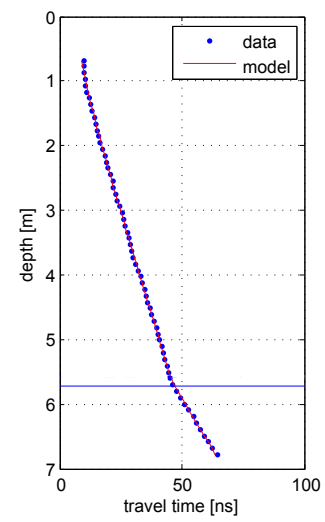

c)

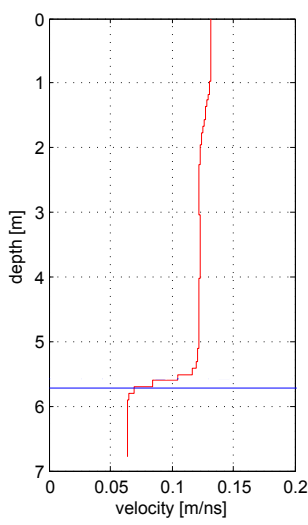

Fig. 3. VRP radar section in a monitoring well on top of a dune (100 MHz nominal frequency) with $1.0 \mathrm{~m}$ antenna offset from the well (a). The amplitude of each trace is normalised in the plot and the picked arrival times are shown as red crosses. Inversion of VRP data: picked travel times (b) and inverted velocity-depth model (c). The groundwater level in the well is shown as blue line.

\subsection{CO profile measurements}

About $20 \mathrm{~km}$ of GPR profiles in a constant-offset setup were acquired in the eastern and central part of the island by using a GSSI SIR 3000 instrument with $80 \mathrm{MHz}$ unshielded and $200 \mathrm{MHz}$ shielded antennas with offsets of 2 and $0.3 \mathrm{~m}$ and trace increments of 0.1 and $0.05 \mathrm{~m}$, respectively (see Fig. 1). Due to the dense vegetation and regulations of the nature protection area, the survey was limited to roads, gravel paths and trails. The exact antenna position and the elevation were tracked by a Trimble 5800 differential global positioning system (DGPS) with base station on the island yielding an accuracy of approx. $1 \mathrm{~cm}$ for the position and $5 \mathrm{~cm}$ for the absolute elevation. At a few locations no DGPS signal was available due to interruptions in communication to the base station or to satellites and the GPR data were not used for analysis. Further, some sections of the $\mathrm{CO}$ profiles were highly disturbed by antenna ringing so that no geological structures could be identified. The ringing was caused either by an electrically conductive ground of the lower marshland that is flooded by seawater from time to time, or by metal installations in the subsurface. Such installations were water pipes, cables, remains of a railway track and in some parts the reinforcement of the road concrete pavement. However, most of the sections showed good data quality with investigation depths of down to $10 \mathrm{~m}$.

Figure 4 shows a GPR section measured from the North Sea over the main dune area in direction of the inner island using two different antennas (profile 1, Fig. 1). Timezero was corrected and gain balancing was performed to remove the time-dependent gain of the GPR device and to counterbalance for spherical spreading. A dewow filter (5 and $20 \mathrm{~ns}$ running mean for 200 and $80 \mathrm{MHz}$ data, respectively) was applied to remove low frequency noise. In addition, the $80 \mathrm{MHz}$ data were lowpass filtered $(120 / 240 \mathrm{MHz})$ to remove high frequency noise. Finally, a depth migration 


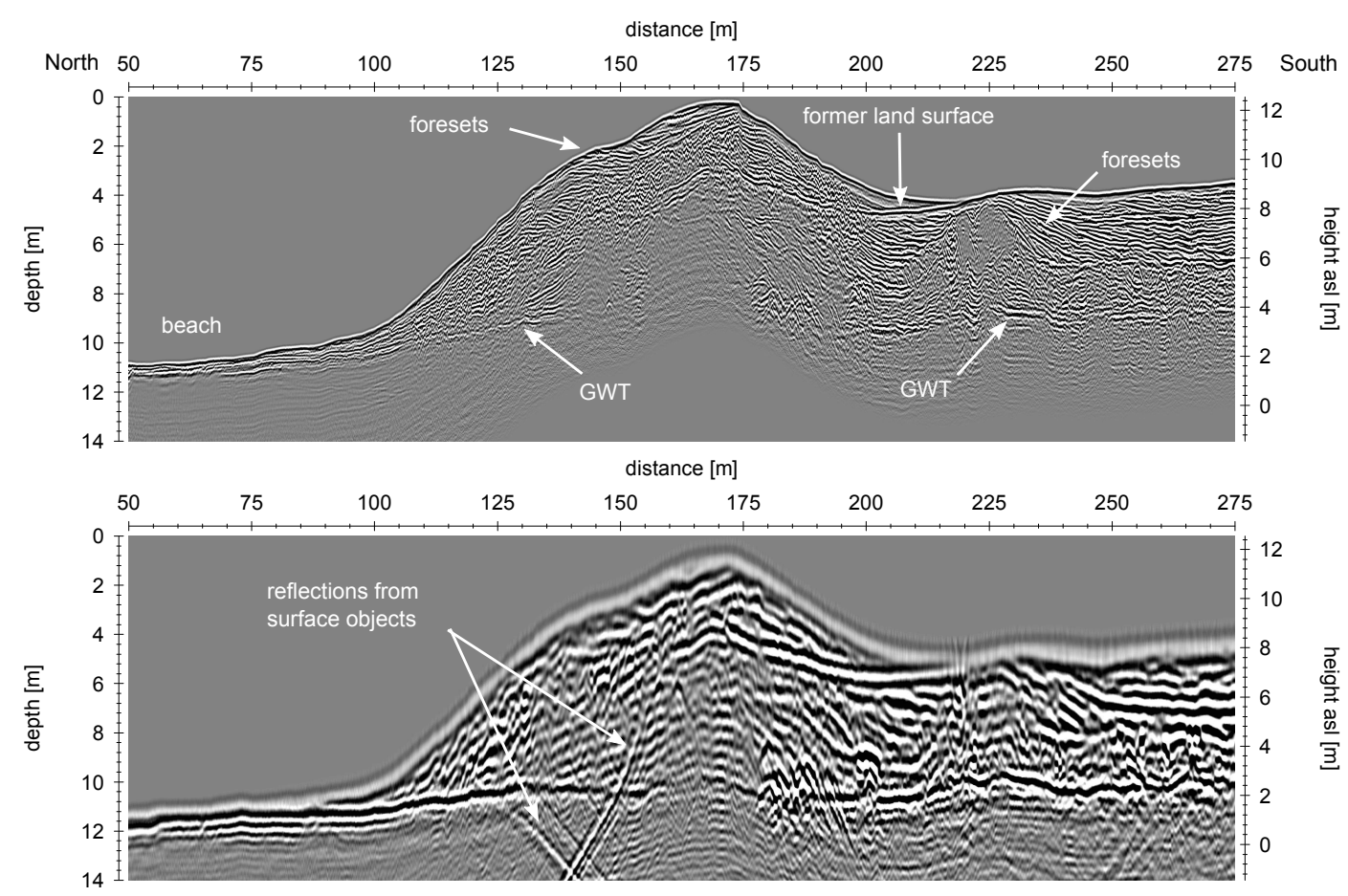

Fig. 4. GPR profile 1 (see Fig. 1 for location) from the North Sea over the main dune in direction of the inner island: $200 \mathrm{MHz}$ (top), $80 \mathrm{MHz}$ (bottom). The data are migrated and topographically corrected. The amplitudes of both sections are normalised for comparison and the vertical axis is exaggerated by a factor of 5 .

was done incorporating the topography (Sandmeier, 2011). A 2D velocity model with $v=0.124 \mathrm{mns}^{-1}$ above and $0.065 \mathrm{~m} \mathrm{~ns}^{-1}$ below the groundwater table was assumed with a smooth change at the interface to account for the transition zone above the groundwater table and to prevent migration artefacts and wavelet distortions of the groundwater reflection. Note that horizontal reverberations in the $80 \mathrm{MHz}$ data following the topography could not be removed by $f-k$ filtering or background removal because this would also extenuate the generally horizontal groundwater reflection as well as horizontal geological reflections. Penetration depth was poor and antenna ringing was strong on the northernmost part of the profile on the beach. This is caused by the high electrical conductivity of the saltwater-saturated sand. When going south over the dune, data quality was very good with penetration depths of $10 \mathrm{~m}$ and more. The $80 \mathrm{MHz}$ data with unshielded antennas show some steeply inclined surface reflections that probably stem from a fence on top of the dune. The groundwater table can be recognised as an almost horizontal reflection at a depth of $10 \mathrm{~m}$ below the maximum elevation of the dune. Above the groundwater table, the GPR reflections are caused by stratigraphic boundaries within the dune. The $200 \mathrm{MHz}$ data provide a very detailed structural map of the dune sedimentation.

A GPR section $(200 \mathrm{MHz})$ of the inner dune region is shown in Fig. 5 (profile 2, Fig. 1). In the upper part (above 1-2 ma.s.l.) cross stratification is dominant whereas in the lower part the stratigraphy is almost horizontal. A strong reflector denoted by GWT follows roughly the large-scale topography and is elevated up to $1 \mathrm{~m}$ in the centre of the profile and descends to both sides. Further, a sharp dominant reflection can be seen at around sea level. A detail of the $\mathrm{CO}$ section is shown in Fig. 6 and the complete section with low exaggeration is available in the Supplement.

\subsection{Drillings and sample analysis}

In addition to near-surface auger sampling, 3 boreholes along GPR profile 2 were driven to a maximum depth of $6 \mathrm{~m}$ by using a drill hammer (positions denoted in Figs. 1 and 5). The lithology is shown in Fig. 7. The humous topsoil and the slightly humous subsoil have a thickness of 10 and $30 \mathrm{~cm}$, respectively. Further down, the sediments consist of moderately calcareous fine to medium sands. They are crossed by several layers with different organic matter content and a $0.1 \mathrm{~m}$ thick peat layer (Fig. 7 , borehole B at $0.8-0.9 \mathrm{~m}$ depth). The sediments above and below the groundwater fluctuation zone show different colours caused by the varying redox potentials in the oxidizing and the reducing environment. At greater depth, the fine to medium grained sand is loaded with shell detritus overlying a $0.2-0.6 \mathrm{~m}$ thick layer of silt loam with a high content of organic matter. Within these loamy deposits that represent the former surface of the tidal flat, small layers of fine to medium sand are included in 


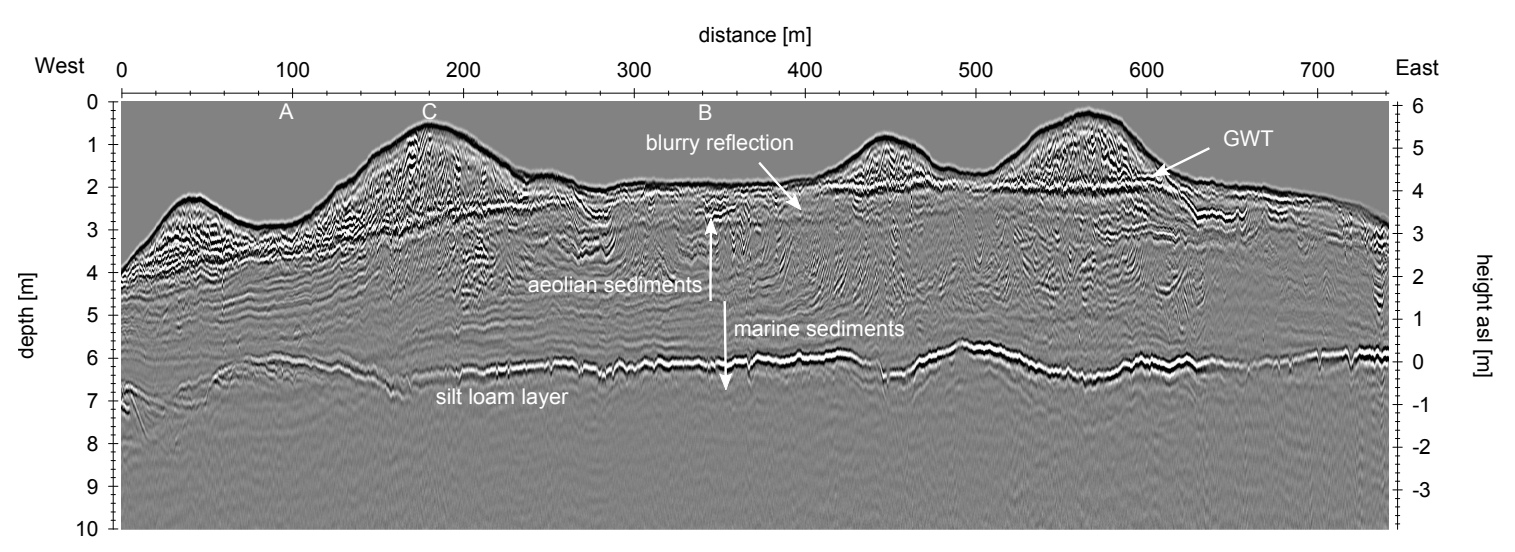

Fig. 5. GPR profile 2 (see Fig. 1 for location), $200 \mathrm{MHz}$. The data are migrated and topographically corrected. The positions of the 3 hand drillings $(\mathrm{A}, \mathrm{B}, \mathrm{C})$ are tagged below the $\mathrm{x}$-axis and the vertical axis is exaggerated by a factor of 25 .

places. Below this layer the fine to medium sand is silty and enriched with shell detritus and interspersed thin clay lenses.

The grain-size distribution of the drill core samples were analysed with a Beckman Coulter LS 13320 laser diffractometer. Characteristic samples for each sedimentological block are plotted in Fig. 8. The sediments of the upper drill core are well sorted and rounded, as identified by microscopic analysis (sample B1 and B4). These sediments are aeolian dune sands that are characterized by accumulation layers as found in the drill cores. The marine sediments directly above and below the silty loam layer (B8) are not sorted that well and have a $20 \%$ silt fraction (B9). Grain densities and porosity of the dune sands were determined to $2.66 \mathrm{~g} \mathrm{~cm}^{-3}$ and $39-42.5 \%$ with a Quantachrome pycnometer for disturbed and loosely packed samples. Further, the capillary rise height of the sand was experimentally determined. The dry sand was filled into a tube and slightly compacted $(\Phi=42 \%)$, put into a water basin and the rise height was observed with time. After 3 days the height of the saturated sand was at $13.5 \mathrm{~cm}$ above the water table and did not change any more. Electrical bulk conductivity was also determined for some water saturated samples and was $0.008 \mathrm{~S} \mathrm{~m}^{-1}$ for the aeolian sand (B4), $0.037 \mathrm{~S} \mathrm{~m}^{-1}$ for the peat (B2), and $0.077 \mathrm{~S} \mathrm{~m}^{-1}$ for the silty loam (B8).

\section{Results and discussion}

\subsection{GPR velocities and hydraulic properties}

Mean radar velocities were determined by CMP and VRP analysis to 0.124 and $0.065 \mathrm{mns}^{-1}$ in the unsaturated and saturated zone corresponding to permittivities of $\varepsilon_{r}=5.9$ and $\varepsilon_{r}=21.6$, respectively (Eq. 2). The values are in good agreement to common radar velocities in similar environments (Møller and Anthony, 2003).

The CRIM formula (Eq. 3) was used to derive the porosity from the bulk permittivity of the saturated zone for which
$\theta_{V}=\Phi$. For this, the permittivity of the matrix was set to the permittivity of quartz $\left(\varepsilon_{r}^{\mathrm{m}}=4.6\right)$ and the permittivity of water to $\varepsilon_{r}^{\mathrm{W}}=84.0$, which is the value at $10^{\circ} \mathrm{C}$ and $100 \mathrm{MHz}$ (Kaatze, 1989). This results in a porosity of $\Phi=35.6 \%$ that corresponds very well to literature values for a compacted fine to medium sand ( $\Phi=35 \%$, Ad-hoc-AG Boden, 2005). The porosities of the sand determined with a pycnometer (39-42.5\%) were higher since disturbed and only slightly compacted samples were analysed. By using the deduced porosity of $\Phi=35.6 \%$, in a second step the water content of the unsaturated zone was calculated to $\theta_{V}=8 \%$. This is slightly lower than the field capacity of a fine to medium sand (Ad-hoc-AG Boden, 2005).

\subsection{Sedimentological structures}

In the CO sections (Figs. 4-6) a variety of reflections can be seen that originate from sedimentological interfaces. They comprise clay, loam and peat layers as well as slight changes in the grain-size distribution, compaction and organic content of the sand in the dune body. These small changes can often hardly be detected in core samples, however, they cause changes in water content and thus dielectric permittivity and yield distinct GPR reflections. These reflections reveal the inner structure and formation history of the sediments as foreset beds and paleosoil horizons within the dunes and former tidal flat surfaces within the marine sediments. In Figs. 5 and 6 we can distinguish an area above 1-2 m a.s.l. with predominantly cross-bedding structures and an area below with predominantly horizontal layering. Cross bedding is typical for dunes but can also occur in marine sediments in the coastal zone and beach ridges (e.g., Nielsen et al., 2009; Lindhorst et al., 2010). However, the inclination of the cross bedding structures in the GPR sections is up to $23^{\circ}$ and they are probably even steeper as the inclination depends on the strike of the GPR profile in relation to the dipping structures. Further, the reflections cross the GWT and can be traced into the dune bodies (see Fig. 6, $x=170-190 \mathrm{~m}$ ). Therefore, we interpret 

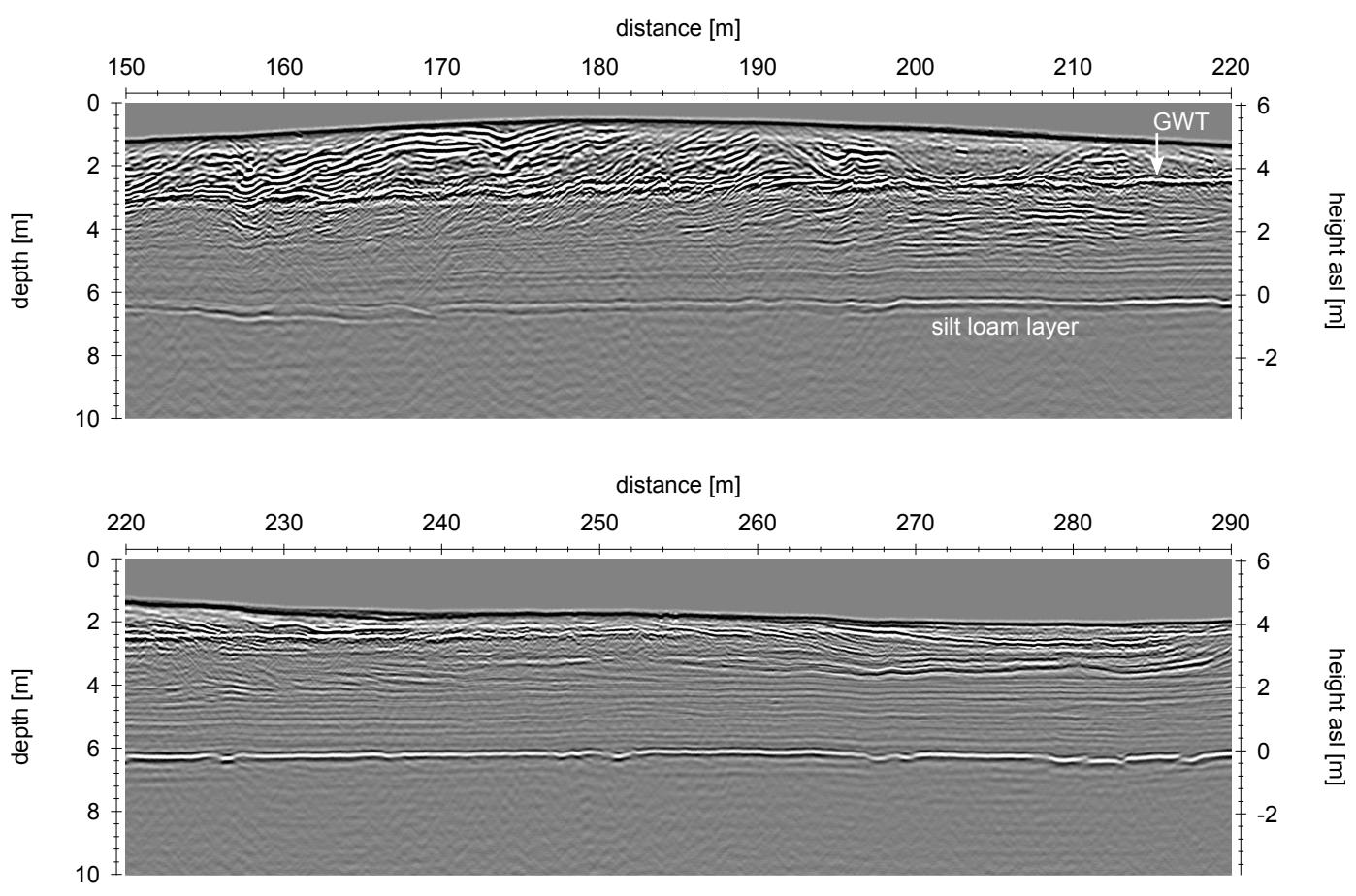

Fig. 6. Detail of GPR profile 2, $200 \mathrm{MHz}$ (Fig. 5) with lower vertical exaggeration. The data are migrated and topographically corrected. The vertical axis is exaggerated by a factor of 2 . The complete profile with this exaggeration is provided in the Supplement.

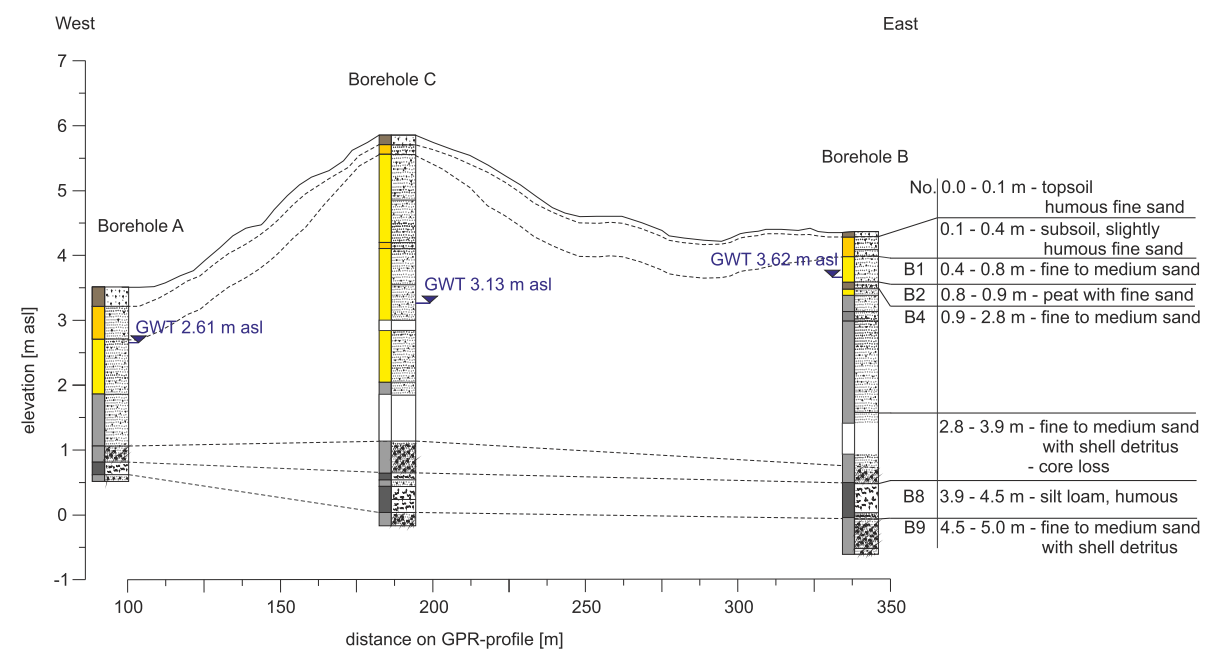

Fig. 7. Lithology of the hand drillings and geological model. The vertical axis is superelevated and the $\mathrm{x}$-coordinates correspond to the $\mathrm{x}$-axis of the radar sections in Figs. 5 and 6. The depths where core loss appeared are in plain white. Groundwater tables and sediment colouring are shown besides lithology. Samples at different depths were taken from drilling B (B1-B9).

the upper area with predominant cross-bedding structures to be aeolian sediments and the area below to be marine sediments. This interpretation is in good agreement to the analysis of the core samples that show shell detritus only for the sediments below $1.5 \mathrm{~m}$ a.s.l. (Fig. 7). In addition, when looking at the grain-size distributions (Fig. 8), the upper sediments (samples B1 and B4) are well sorted and the lower sediments (sample B8 and B9) are less sorted. The distinct reflector at approximately $0 \mathrm{ma}$ a.s.l. is caused by the high electrical conductivity of a $20-60 \mathrm{~cm}$ thick silt loam layer that is interpreted as a former tidal flat surface and hydraulically acts as an aquitard. A detailed look at this reflector (Fig. 6) shows discontinuities that are interpreted as erosion channels of the former tideways. These structures are a few decimeters to meters wide and up to $40 \mathrm{~cm}$ deep so that the layer is likely to show some leakage to water flow. 


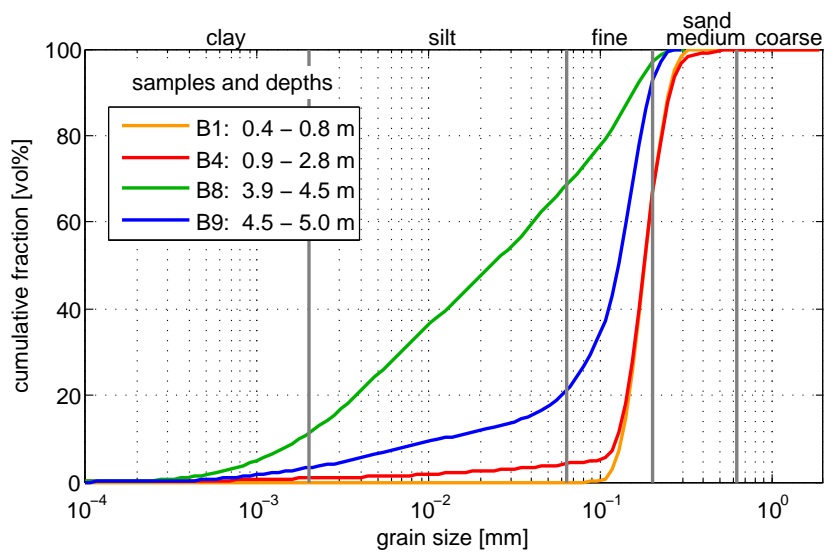

Fig. 8. Grain-size distribution of the samples from borehole B.

This finding is confirmed by pumping tests (Sulzbacher et al., 2012). They show that in some areas this layer separates the upper unconfined aquifer from a lower confined aquifer and in other areas there is a leakage.

The reflection from the silt loam was detectable in most $\mathrm{CO}$ profiles in an area of approx. $1 \mathrm{~km}^{2}$ in the central part of the investigation area. The onsets were picked and the travel times transformed into depth by using the correct radar velocities and DGPS elevations (Fig. 9). The layer shows some topography and fluctuates between -1.4 and $0.8 \mathrm{~m}$ a.s.l. and was directly included in the hydraulic model (Sulzbacher et al., 2012).

\subsection{Groundwater table of the freshwater lens}

The groundwater table causes a strong reflection due to the high contrast in dielectric permittivity and can be seen in Figs. 4-6. The groundwater reflection appears stronger in the low frequency data than in the high frequency data (see Fig. 4). The reason for this is the lower damping for low radar frequencies and the gradual increase of water content (and dielectric permittivity) in the transition zone above the groundwater table (Harari, 1996) that causes a frequencydependent reflection coefficient. The lower the frequency, i.e. the longer the wavelength, the sharper is the contrast for the waves and the stronger is the reflection. On the other hand, the resolution is worse for the $80 \mathrm{MHz}$ data. Further, for shallow groundwater tables, the reflection is masked by the longer primary wavelet for this antenna. Thus, a combination of both antennas shows to be a flexible way to map the groundwater table with changing coverage height of dune sediments. For shallow depths to the GWT, the $200 \mathrm{MHz}$ data were used, whereas the $80 \mathrm{MHz}$ data were used at locations where the depth of investigation of the $200 \mathrm{MHz}$ antennas was not sufficiently large. No significant difference of the picked GWT could be recognised between both antennas as the first-time arrivals were picked. The groundwater table shows to be shallow near the coast and rises towards the inner dune part of the island (Fig. 4). The GPR section in the central area of the island (Fig. 5) shows a curved GWT reflection crossing the dipping sedimentological reflections (Fig. 6, $x=170-190 \mathrm{~m}$ ). It is about $1 \mathrm{~m}$ higher in the middle of the profile and sinks down to both sides where the land surface is lower.

The groundwater table was picked in the $\mathrm{CO}$ sections where clearly visible, i.e. on profiles with good data quality and low dune coverage (i.e. $\lesssim 10 \mathrm{~m}$ ) and the travel times were transformed into depths. GPR does not detect the pressure height of the groundwater table, i.e. the level of a free water surface in a borehole, but is sensitive to changes of water content and thus the change from unsaturated to fully saturated sediments. Therefore, GPR - as every geophysical technique - yields a higher groundwater table than the pressure heads in wells. Figure 10 compares the uncorrected GPR water tables to the pressure heads in neighbouring observation wells. All wells closer than $25 \mathrm{~m}$ to the GPR profiles were included and the readings were done within 2 weeks after the GPR measurements so that only minor deviation of a few centimetres remains from temporal changes. There is a good correlation between both data, however, GPR water tables are systematically higher than the pressure heads of the observation wells. The offset was determined by regression analysis to be $45 \mathrm{~cm}$ and shifting the GPR data by this value reduces the root-mean-square (RMS) deviation between wells and GPR from $50 \mathrm{~cm}$ to $14 \mathrm{~cm}$. The shift is mainly caused by the capillary rise of the water above the pressure head. The capillary fringe as the saturated zone above the pressure head (de Marsily, 1986) was assessed to $13.5 \mathrm{~cm}$ in an experiment as described above. However, the porosity of the disturbed sand sample was higher than in situ ( $\Phi=42 \%$ vs. $36 \%$ ). The capillary fringe is supposed to be significantly larger for compacted sediments in the field (Ad-hoc-AG Boden, 2005). In the transition zone above the capillary fringe, the water content typically decreases from saturation to field capacity. The width and gradient of this transition zone defines the exact reflection characteristics of the GPR wavelets and thus has also an influence on the shift between GPR measured water tables and pressure heads. Further contributions to the shift may be time-zero correction of the GPR data and picking errors or inaccuracies of the velocity model. The latter would cause a misfit that systematically rises with increasing depth of the GWT below ground surface. Such a trend is not obvious in Fig. 10 so that the velocity model seems reasonable. After correcting for the empirically determined shift of $45 \mathrm{~cm}$, the GPR water tables correspond to pressure heads of a free groundwater table and are shown in Fig. 11.

In the centre of the island, the groundwater table is found to be up to $3.5 \mathrm{~m}$ above sea level. On a large scale, it follows roughly the topography of the island, i.e. it is higher in the dune areas and decreases towards the coastal line and the lower marshland. Local depressions and large gradients of the GWT can be seen in the area of a deep dune valley 


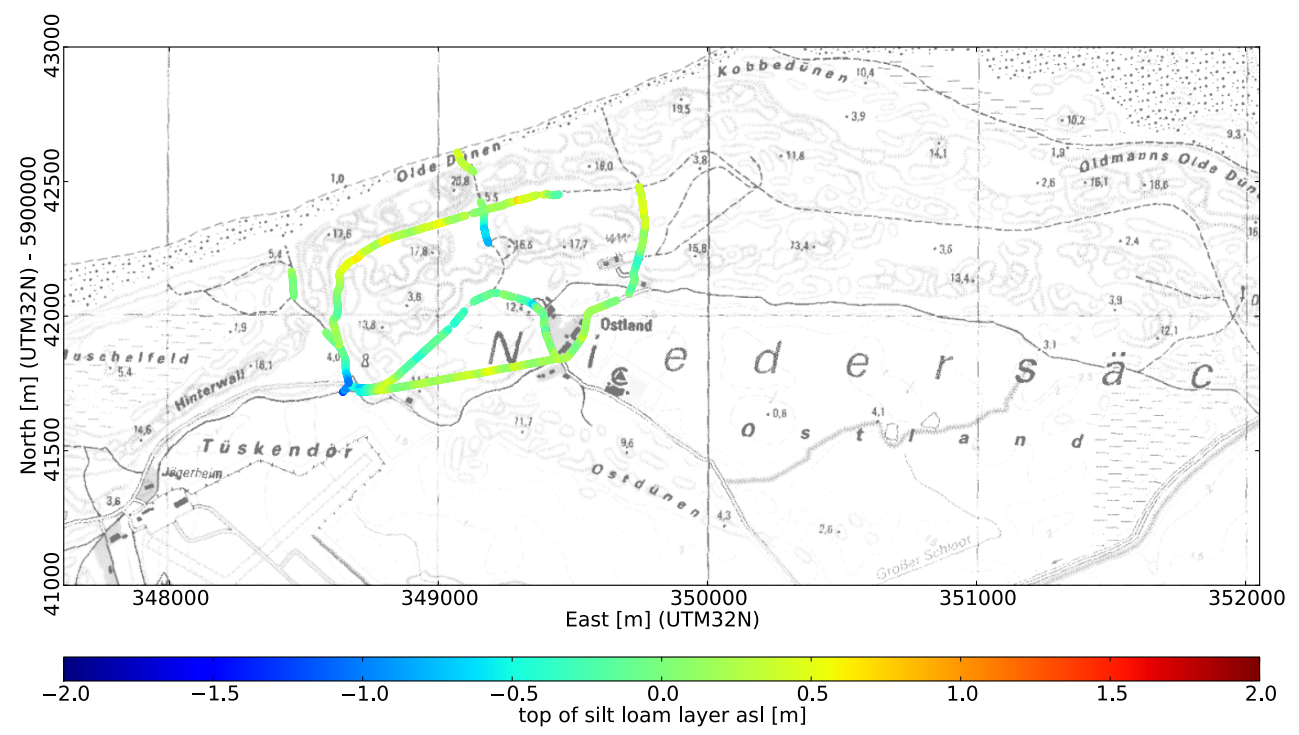

Fig. 9. Top of the silt loam layer from clearly visible GPR reflections.

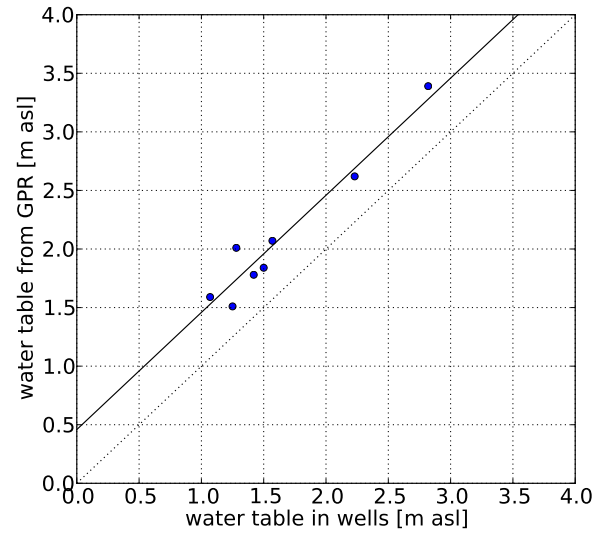

Fig. 10. Water tables deduced from GPR vs. water tables from observation wells (blue dots) and regression (solid line). The closest GPR measurements within a $25 \mathrm{~m}$ radius around the wells were taken for comparison.

(349750E, 5942500N) and particularly around the pumping stations of the local water supplier (see Fig. 1 for positions). Similar gradients can also be confirmed for some observation wells that can be found in close vicinity one to another (e.g., 350100E, 5942700N).

The results are similar to the findings of Tronicke et al. (1999) who investigated the freshwater lens of Spiekeroog, another East Frisian barrier island. They found the water table to be higher than $1.5 \mathrm{~m}$ a.s.l. in the centre of this island and they observed lower water tables in the area of water production wells. However, the geology of this island is different to Borkum, which explains the different thickness of the freshwater lens and the resulting elevation of the GWT.
The water table deduced from GPR was used to extrapolate the pressure heads of the observation wells. In areas with large well spacing, GPR data were used as additional nodes to construct the groundwater table that was needed for calibration of the hydraulic model (Sulzbacher et al., 2012). This was the case in the area of the central island.

From the GPR measured groundwater tables, the thickness of the freshwater lens can be deduced by using the HerzbergGhyben relation (Eq. 1). In the region of the "CLIWAT II" drilling (see Fig. 1), the height of the groundwater table is found to be $1.5 \mathrm{~m}$ a.s.l. resulting in a $61.5 \mathrm{~m}$ thick freshwater lens. This is in good accordance to the findings of ERT measurements in the vertical electrode chain that has been installed in the borehole and shows a strong increase of the electrical conductivity between 48 and $61 \mathrm{~m}$ depths (Grinat et al., 2010). At the highest GWT elevation of $3.5 \mathrm{~m}$ a.s.l. in the central dune area, the equation predicts a $143.5 \mathrm{~m}$ thick freshwater lens. However, one has to consider that the relation is only a simple description and does not take into account the complex geology, varying salt concentrations in the subsurface and cannot describe non-stationary conditions. Airborn EM measurements and numerical simulations have shown that the saltwater-freshwater interface is shallower than predicted by the simple Herzberg-Ghyben equation (Sulzbacher et al., 2012).

An interesting feature can be seen in Fig. 5: in the centre of the profile, a weak blurry reflection can be recognised below the GWT reflection. To the sides of the profile it is not visible as it is probably superimposed by sedimentological reflections. This weak reflection is not a multiple reflection as it does not follow topography. Instead it is more or less parallel to the groundwater reflection and might be caused by graincoating iron minerals. These minerals can typically be found 


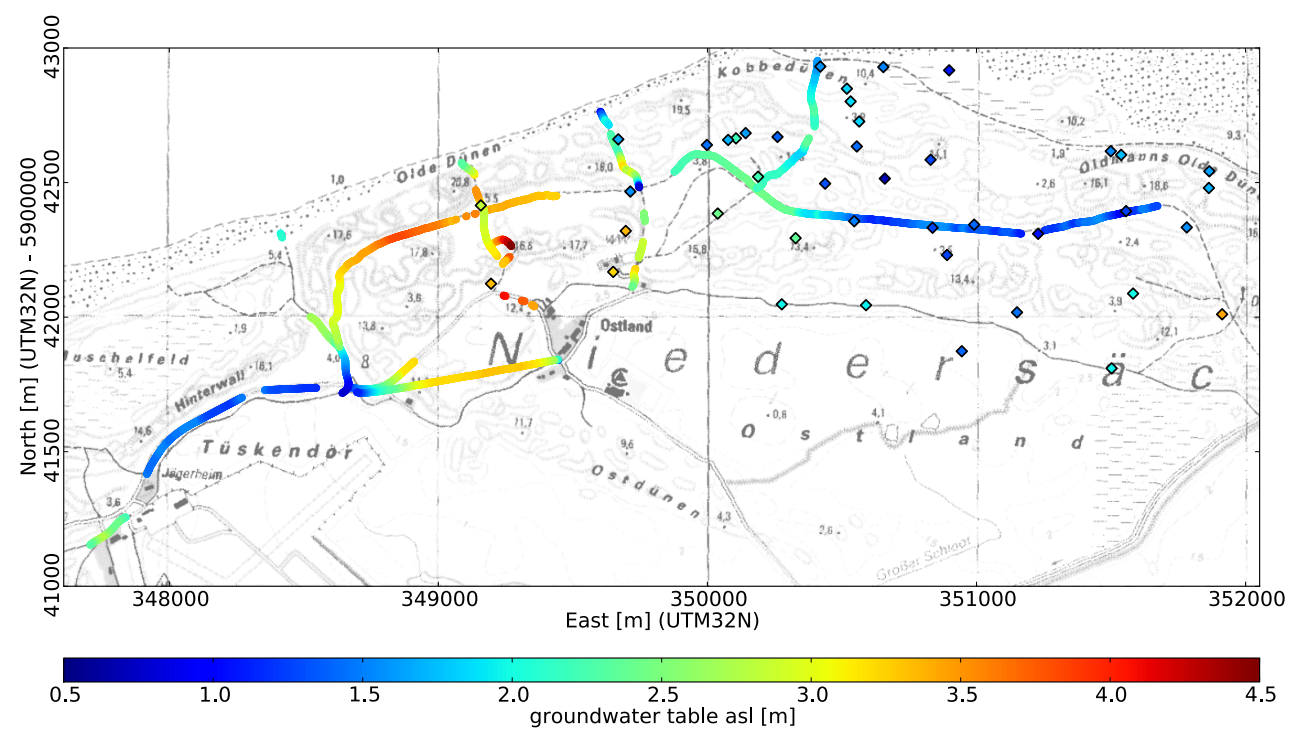

Fig. 11. Watertable of the freshwater lens in the eastern part of the island deduced from corrected GPR data (lines) and water tables in the observation wells (diamonds).

in the groundwater fluctuation zone that is characterised by changing redox potentials and shows brown-yellow colours (Fig. 7). In the permanently saturated zone with reducing environment, the colour of the sand is grey, i.e. the grains have no significant iron-mineral coating. As grain-coating iron minerals have an impact on the dielectric properties of quartz sand (Josh et al., 2011), the changing redox conditions may cause this reflection.

\section{Conclusions and outlook}

We used GPR to investigate the shape of the eastern freshwater lens on Borkum island and to reveal hydraulically relevant subsurface structures. CMP and VRP measurements were applied to deduce radar velocities in the subsurface. A simple velocity model with $v=0.124 \mathrm{mns}^{-1}$ above the groundwater table and $0.065 \mathrm{mns}^{-1}$ below showed to be appropriate. From these velocities the porosities of the dune sediments and the water content in the unsaturated zone were derived. The velocity model was also used for a depth migration of the GPR data and to transform the travel times into depths. Low frequency data show stronger reflections at the groundwater table than high frequency data, which is interpreted as an effect of the transition zone above the groundwater table and an increasing absorption with frequency. After correcting for capillary rise and systematic effects by a calibration with neighbouring wells, the derived groundwater tables agree with the observations at the monitoring wells within an RMS error of $14 \mathrm{~cm}$. Despite the topography of the island with up to $16 \mathrm{~m}$ high dunes on the GPR profiles, the deviation is small. In the centre of the island, the groundwater table is found to be up to $3.5 \mathrm{~m}$ above sea level and it sinks down to sea level towards the coast line and marshland. Local depressions are observed in the region of a deep dune valley and around the pumping stations of the local water supplier and show relatively steep gradients.

The water tables deduced from GPR were used as additional nodes for interpolation of the GWT in areas with no or only few observation wells. This was especially the case for the centre of the island, between the extraction well fields of the western and eastern water works, where GPR investigation contributed to a more reliable model of the freshwaterlens surface (see Sulzbacher et al., 2012).

GPR gives also valuable insights in the sediment structures and can map hydraulically significant layers, particularly if combined with boreholes. Highly permeable aeolian dune sediments could be distinguished from less permeable marine sediments by their inner structure and the findings contributed to the development of the conceptual hydrological model, i.e. a sandy medium with intercalated clay and silt layers (Sulzbacher et al., 2012). A hydraulically less conductive silt loam layer was detected and interpreted as a former tidal flat surface. Moreover, GPR revealed erosion channels, so that it hydraulically acts as aquiclude with some leakage and the depth and extension of this pronounced layer was directly included in the model.

GPR data along measuring profiles were collected in a larger area $\left(\approx 6 \mathrm{~km}^{2}\right)$ in only a few days. As the effort of such investigations is acceptable, repeated surveys could be done over a longer period. This will give detailed information how the surface of the freshwater lens behaves with time.

The weak and blurry reflection below the GWT might be caused by iron-mineral coatings that are related to changing redox potentials. If so, it will be possible to reveal 
past groundwater fluctuations by GPR under certain conditions. However, this hypothesis needs to be tested, e.g., by analysing the dielectric and chemical properties of undisturbed sand samples.

Combined interpretation or inversion of different geophysical techniques is promising for the future. For instance, a comparison of the top of the freshwater lens mapped by GPR with the saltwater-freshwater interface, as derived by airborne EM or ERT (Sulzbacher et al., 2012; Grinat et al., 2010), can be used to evaluate the Herzberg-Ghyben relation. Discrepancies suggest a subsurface that is not homogeneous and interpreting the discrepancies may reveal further details about the properties of the whole aquifer and can be used to calibrate and improve groundwater models. A further combination with MRS (Günther and Müller-Petke, 2012) may be used to characterise the hydraulic properties of sediments as both techniques are sensitive to water distributed in different pore sizes.

\section{Supplementary material related to this article is available online at: http://www.hydrol-earth-syst-sci.net/ 17/519/2013/hess-17-519-2013-supplement.pdf.}

Acknowledgements. The authors would like to thank Dieter Epping, Raphael Holland and Detlef Vogel for assisting the GPR measurements, the student Matthias Singer for assisting the core pile drillings and the municipal water supplier of Borkum for logistically supporting the field campaign. We like to acknowledge Cornelia Müller and Matthias Halisch for the pycnometer measurements, Franz Binot for his hints concerning geology and Sebastian Winter for providing the data of the monitoring wells and his hydrogeological advice while planing the GPR investigation. Thanks to Markus Loewer for proof-reading the manuscript. We would like to acknowledge Ingelise Møller and an anonymous reviewer as well as the editor for their constructive comments that helped to significantly improve the manuscript.

Edited by: F. Jørgensen

\section{References}

Ad-hoc-AG Boden: Bodenkundliche Kartieranleitung, 5th Edn., Hannover, Germany, 2005.

Annan, A. P.: Ground penetrating radar, in: Near Surface Geophysics, Vol. 13 of Investigations in Geophysics, Society of Exploration Geophysics, Tulsa, OK, 357-438, 2005.

Bennett, M. R., Cassidy, N. J., and Pile, J.: Internal structure of a barrier beach as revealed by ground penetrating radar (GPR): Chesil beach, UK, Geomorphology, 104, 218-229, 2009.

Bristow, C., Bailey, S., and Lancaster, N.: The sedimentary structure on linear sand dunes, Nature, 406, 56-59, 2000.

Cassiani, G., Fusi, N., Susanni, D., and Deiana, R.: Vertical radar profiling for the assessment of landfill capping effectiveness, Near Surf. Geophys., 6, 133-142, 2008.
Clement, W. P. and Knoll, M. D.: Traveltime inversion of vertical radar profiles, Geophysics, 71, K67-K76, 2006.

van Dam, R.: Landform characterization using geophysics - recent advantages, applications, and emerging tools, Geomorphology, 137, 57-73, 2012.

Dix, C. H.: Seismic velocities from surface measurements, Geophysics, 20, 68-86, 1955.

Doolittle, J. A., Jenkinson, B., Hopkins, D., Ulmer, M., and Tuttle, W.: Hydropedological investigations with ground-penetrating radar (GPR): estimating water-table depths and local groundwater flow pattern in areas of coarse-textured soils, Geoderma, 131, 317-329, 2006.

Ernst, J. R., Green, A. G., Maurer, H., and Holliger, K.: Application of a new 2D time-domain full-waveform inversion scheme to crosshole radar data, Geophysics, 72, J53-J64, 2007.

Grinat, M., Südekum, W., Epping, D., Grelle, T., and Meyer, R.: An automated electrical resistivity tomography system to monitor the freshwater/saltwater zone on a North Sea Island, in: Ext. Abstr., Near Surface 2010: 16th European Meeting of Environmental and Engineering Geophysics, Zurich, 6-8 September 2010, 2010.

Günther, T. and Müller-Petke, M.: Hydraulic properties at the North Sea island of Borkum derived from joint inversion of magnetic resonance and electrical resistivity soundings, Hydrol. Earth Syst. Sci., 16, 3279-3291, doi:10.5194/hess-16-32792012, 2012.

Harari, Z.: Ground-penetrating radar (GPR) for imaging stratigraphic features and groundwater in sand dunes, J. Appl. Geophys., 36, 43-52, 1996.

Hardage, B. A.: Vertical Seismic Profiling: Principles, Handbook of Geophysical Exploration, Seismic exploration, 3rd Edn., 14, Elsevier, Amsterdam, 2000.

Herzberg, B.: Die Wasserversorgung einiger Nordseebäder, J. Gasbeleucht. Wasserversorg., Berlin, 44, 815-819, 1901.

Josh, M., Lintern, M. J., Kepic, A. W., and Verrall, M.: Impact of grain-coating iron minerals on dielectric response of quartz sand and implications for ground-penetrating radar, Geophysics, 76, J27-J34, 2011

Kaatze, U.: Complex permittivity of water as a function of frequency and temperature, J. Chem. Eng. Data, 34, 372-374, 1989.

Keilhack, K. and Wildvang, D.: Bl. Borkum, Juist-West, JuistOst u. Norderney, Vol. 914, 1010, 1011, 915, 916, 820, 821 of Erläuterungen zur Geologischen Karte von Preußen und benachbarten deutschen Ländern, Preußische Geologische Landesanstalt, Berlin, 1925.

Klotzsche, A., van der Kruk, J., Meles, G. A., Doetsch, J., and Maurer, H., and Linde, N.: Full-waveform inversion of cross-hole ground-penetrating radar data to characterize a gravel aquifer close to the Thur River, Switzerland, Near Surf. Geophys., 8, 635-649, 2010.

Kruse, S. E., Schneider, J. C., Inman, J. A., and Allen, J. A.: Ground penetrating radar imaging of the freshwater/saltwater interface on a carbonate island, Key Largo, Florida, Ext. Abstr., GPR 2000: the 8th International Conference on Ground Penetrating Radar; Goldcoast, 4084, 335-340, 2000

Lindhorst, S., Fürstenau, J., Haas, C., and Betzler, C.: Anatomy and sedimentary model of a hooked spit (Sylt, southern North Sea), Sedimentology, 57, 935-955, 2010. 
de Marsily, C.: Quantitative Hydrogeology, Groundwater for Engineers, Academic Press Inc., San Diego, California, 1986.

Møller, I. and Anthony, D.: A GPR study of sedimentary structures within a transgressive coastal barrier along the Danish North Sea coast, Geol. Soc. London Spec. Publ., 211, 55-65, 2003.

Neal, A.: Ground-penetrating radar and its use in sedimentology: principles, problems and progress, Earth-Sci. Rev., 66, 261-330, 2004.

Nielsen, L., Møller, I., Nielsen, L. H., Johannessen, P., Pejrup, M., Andersen, T. J., and Korshøj, J. S.: Integrating groundpenetrating radar and borehole data from a Wadden Sea barrier island, J. Appl. Geophys., 68, 47-59, 2009.

Rejiba, F., Bobée, C., Maugis, P., and Camerlynck, C.: GPR imaging of a sand dune aquifer: a case study in the niayes ecoregion of Tanma, Senegal, J. Appl. Geophys., 81, 16-20, doi:10.1016/j.jappgeo.2011.09.015, 2012.

Sandmeier, K. J.: Reflex-Win Version 4.2, Windows $9 \mathrm{x} / \mathrm{NT} / 2000 / \mathrm{XP} / 7$-program for the processing of seismic, acoustic or electromagnetic reflection, refraction and transmission data, Sandmeier Scientific Software, available at: www.sandmeier-geo.de (last access: 5 February 2013), Germany, 2011.

Shen, L. C., Savre, W. C., Price, J. M., and Athavale, K.: Dielectric properties of reservoir rocks at ultra-high frequencies, Geophysics, 50, 692-704, 1985.

Siemon, B., Christiansen, A., and Auken, E.: A review of helicopterborne electromagnetic methods for groundwater exploration, Near Surf. Geophys., 7, 629-646, 2009.
Sulzbacher, H., Wiederhold, H., Siemon, B., Grinat, M., Igel, J., Burschil, T., Günther, T., and Hinsby, K.: Numerical modelling of climate change impacts on freshwater lenses on the North Sea Island of Borkum using hydrological and geophysical methods, Hydrol. Earth Syst. Sci., 16, 3621-3643, doi:10.5194/hess-163621-2012, 2012.

Topp, G. C., Davis, J. L., and Annan, A. P.: Electromagnetic determination of soil water content: measurements in coaxial transmission lines, Water Resour. Res., 16, 574-582, 1980.

Tronicke, J. and Knoll, M. D.: Vertical radar profiling: influence of survey geometry on first-arrival traveltimes and amplitudes, J. Appl. Geophys., 57, 179-191, 2005.

Tronicke, J., Blindow, N., Groß, R., and Lange, M. A.: Joint application of the surface electrical resistivity- and GPR-measurements for groundwater exploration on the island of Spiekeroog - Northern Germany, J. Hydrol., 223, 44-53, 1999.

Tronicke, J., Holliger, K., Barrash, W., and Knoll, M.: Multivariate analysis of cross-hole georadar velocity and attenuation tomograms for aquifer zonation, Water Resour. Res., 40, W01519, doi:10.1029/2003WR002031, 2004.

Yilmaz, Ö.: Seismic data analysis: processing, inversion, and interpretation of seismic data, Society of Exploration Geophysics, Tulsa, OK, 2001. 